\title{
Reasons and Realities of Health and Geographical Inequality in India: A Study of Inter-State Variations
}

\author{
Dalip Kumar \\ National Council of Applied Economic Research, New Delhi, India \\ Email:dr.dkumar63@gmail.com
}

Received: 24 November 2020; Revised: 20 February 2021; Accepted: 20 February 2021

\begin{abstract}
The paper is an attempt to explain the global regional inequality of health indicators and regional variation among Indian states. This analysis will cover through a set of health indicators (mortality and morbidity) like crude birth rate (CBR), crude death rate (CDR), infant mortality rate (IMR), maternal mortality rate (MMR), life expectancy and total fertility rates (TFR). The paper also provides a comparison of public expenditures on health with that of health expenditure in the private sector in India with those of other countries. This article highlights the dimensions and extent of inequities health indicators. The analysis in this study suggests that much of the problem for low health status in these states is also due to low health expenditure which impacts adversely on the health indicators.
\end{abstract}

Keywords: health, expenditure, inequality, morbidity, mortality, India

JEL Codes: H8, I14, I19, J11, J19

\section{Introduction}

Health is one of the most important components of human development as well as human happiness (UNDP, 2020). Good health ensures employability of the labour force as well as the production and growth in gross domestic product (GDP) and per capital income required for better quality of life (ILO, 2020). Every nation, developed or developing, must provide health services to its population as every individual cannot afford to get better health services on his own. It is the prime duty of government in the welfare state to provide services for good health of its citizens, especially of the dealer section. The health infrastructure, number of doctors, nursing staff, immunization, and research and development (R\&D) programme and all that become clear if we look at some health aspects like crude birth rate (CBR), crude death rate (CDR), infant mortality rate (IMR), Life expectancy, percentage GDP expenditure, etc. Here, with the help of data presented in the Table 1 would like to show the regional inequality in all these important indicators. In this paper an attempt is made to assess the health status of the major states through a set of health indicators. A person's capability to avoid undernourishment may depend not merely on intake of food, but also on the person's access to health care, medical facilities, elementary education, and drinking water \& sanitation facilities (Dreze \& Sen, 1989). Good health is necessary for effective participation in economic and social activities and helps in achieving higher levels of human development (Sharma \& Vijay Kumar, 2008). The most fundamental causes of health disparities are socio-economic disparities (Link \& Phelan, 1995). The distribution of income within countries and states has been linked to rates of

Copyright (C2021 Dalip Kumar

DOI: https://doi.org/10.37256/redr.212021724

This is an open-access article distributed under a CC BY license

(Creative Commons Attribution 4.0 International License)

https://creativecommons.org/licenses/by/4.0/ 
mortality (Kaplan et al., 1996; Fiscella \& Franks, 1997).

\section{Health indicators: Concept}

Health indicators are summary measures that are designed to describe aspects of health or health system performance. Development of health sector is the essence of human and social development. It is a 'human centered' approach towards the development. Health is related to physical, mental, economic, and social well-being of an individual (UNDP, 2020). Health status provides a broad overview of morbidity and mortality patterns of communicable and non-communicable diseases. Health status is generally measured by health indicators in terms of life expectancy at birth, infant mortality rate, total fertility rate, maternal mortality rate crude birth rate and crude death rate. Investment and reforms in health sector not only leads to the improvement in quality of life but also to human resource development which in turn contributes to various sectors of national economy. Health covers a wide range of activities like population control, family planning, prevention of food adulteration, drug control, immunization and eradication of major communicable and non-communicable diseases. India's health sector has been generating over more than one decade of rapid health sector growth. Despite health sector growth, India has high IMR and low level of life expectancy. There are also striking inter-state variations-Kerala's health indicators are comparable to developed countries, while Orissa has one of the highest maternal mortality rate (MMR) in the world. A major problem has been the consistent under-funding of public health services, by both central and state governments, which share the responsibility for the provision and financing of health care in India. Economic historians interested in health may help us to understand the relationship of inequality and health (Nancy \& Newman, 2002). Poverty is directly linked with poor health (Adena \& Myck, 2014).

Health has many dimensions, and it may be imperative at this stage to refer to a variety of indicators of health status rather than select one as preferred. The most cited health indicator is life expectancy. It has the appeal of an intrinsic capability on which personal welfare depends (Sen, 1998). Health is a state of complete physical, mental, and social well-being and not merely the absence of disease or infirmity. The indicators of health status, the birth and death rates are more reflective of the demographic changes taking place in the country. The life expectancy and the infant mortality rate are better indicators of the health status of the population. A look at the relationship among these four indicators is sufficient to confirm that these indicators are changing over the time. Poverty is often linked with poor health.

\section{Regional inequality in health indicators}

The health status is generally measured in terms of crude birth rate and crude death rate, infant mortality rate, life expectancy at birth, and MMR. Health has many dimensions, and it may be imperative at this stage to refer a variety of indicators of health status rather than select one as preferred.

Table 1. Global regional inequality in health sector

\begin{tabular}{ccccccccc}
\hline $\begin{array}{c}\text { Sr. } \\
\text { No. }\end{array}$ & Countries & $\begin{array}{c}\text { CBR/1000 } \\
\text { population } \\
(2018)\end{array}$ & $\begin{array}{c}\text { CDR/1000 } \\
\text { population } \\
(2018)\end{array}$ & $\begin{array}{c}\text { IMR/1000 live } \\
\text { birth 2018 }\end{array}$ & $\begin{array}{c}\text { Life } \\
\text { Expectancy } \\
2017\end{array}$ & $\begin{array}{c}\text { MMR/100000 } \\
\text { live birth, } \\
2017\end{array}$ & $\begin{array}{c}\text { \% GDP Expenditure } \\
\text { on Health Care } \\
\text { 2018 }\end{array}$ & $\begin{array}{c}\text { Per capita health } \\
\text { Expenditure } \\
\text { (US \$) in 2018 }\end{array}$ \\
\hline 1 & Japan & 7.7 & 9.8 & 1.9 & 85.3 & 5 & 10.94 & 4,766 \\
2 & Singapore & 8.6 & 5 & 2.3 & 84.7 & 8 & 4.44 & 2,280 \\
3 & Germany & 8.6 & 11.7 & 3.3 & 81.88 & 7 & 11.25 & 5,987 \\
4 & Canada & 10.3 & 8.7 & 4.3 & 82.96 & 10 & 10.57 & 4,974 \\
5 & Russia & 11 & 13.5 & 6.5 & 72.99 & 17 & 5.34 & 1,514 \\
6 & UK & 12.1 & 9.4 & 4.1 & 81.77 & 7 & 9.63 & 4,070 \\
7 & China & 12.3 & 7 & 11.4 & 77.47 & 29 & 5.15 & 688 \\
8 & USA & 12.5 & 8.2 & 5.3 & 79.11 & 19 & 17.06 & 10,586 \\
9 & Brazil & 14.1 & 6.7 & 15.9 & 76.57 & 60 & 9.47 & 1,282 \\
10 & India & 19 & 7.3 & 35.4 & 70.4 & 145 & 3.53 & 209 \\
& World & 19 & 7.54 & 29.26 & 73.2 & 211 & 9.88 & 999 \\
\hline
\end{tabular}

Source: WHO (2020) \& World Bank (2015). 
Table 2. Regional inequality of CBR, CDR and IMR (1000 population) in India 2000-2018

\begin{tabular}{|c|c|c|c|c|c|c|c|c|c|c|c|c|c|}
\hline \multirow{3}{*}{$\begin{array}{l}\text { Sr. } \\
\text { No. }\end{array}$} & \multirow{3}{*}{ States } & \multicolumn{3}{|c|}{ CBR } & \multicolumn{3}{|c|}{ CDR } & \multicolumn{3}{|c|}{ IMR } & \multirow{2}{*}{\multicolumn{3}{|c|}{$\begin{array}{l}\text { Absolute Changes during } \\
\text { Year } 2000 \text { to } 2018\end{array}$}} \\
\hline & & \multirow{2}{*}{$\begin{array}{l}2000 \\
\text { Total }\end{array}$} & \multirow{2}{*}{$\begin{array}{l}2013 \\
\text { Total }\end{array}$} & \multirow{2}{*}{$\begin{array}{l}2018 \\
\text { Total }\end{array}$} & \multirow{2}{*}{$\begin{array}{l}2000 \\
\text { Total }\end{array}$} & \multirow{2}{*}{$\begin{array}{l}2013 \\
\text { Total }\end{array}$} & \multirow{2}{*}{$\begin{array}{l}2018 \\
\text { Total }\end{array}$} & \multirow{2}{*}{$\begin{array}{l}2000 \\
\text { Total }\end{array}$} & \multirow{2}{*}{$\begin{array}{l}2013 \\
\text { Total }\end{array}$} & \multirow{2}{*}{$\begin{array}{l}2018 \\
\text { Total }\end{array}$} & & & \\
\hline & & & & & & & & & & & CBR & $\mathrm{CDR}$ & IMR \\
\hline 1 & Andhra Pradesh (AP) & 21.30 & 17.40 & 16.00 & 8.2 & 7.3 & 6.7 & 65.0 & 39.0 & 29.0 & 5.30 & 1.5 & 36.0 \\
\hline 2 & Assam & 26.90 & 22.40 & 21.10 & 9.6 & 7.8 & 6.4 & 75.0 & 54.0 & 41.0 & 5.80 & 3.2 & 34.0 \\
\hline 3 & Bihar & 31.90 & 27.60 & 26.20 & 8.8 & 6.6 & 5.8 & 62.0 & 42.0 & 32.0 & 5.70 & 3.0 & 30.0 \\
\hline 4 & Gujarat & 25.20 & 20.80 & 19.70 & 9.7 & 6.5 & 5.9 & 62.0 & 36.0 & 28.0 & 5.50 & 3.8 & 34.0 \\
\hline 5 & Haryana & 26.90 & 21.30 & 20.30 & 7.5 & 6.3 & 5.9 & 67.0 & 41.0 & 30.0 & 6.60 & 1.6 & 37.0 \\
\hline 6 & Karnataka & 22.00 & 18.30 & 17.20 & 7.8 & 7.0 & 6.3 & 57.0 & 31.0 & 23.0 & 4.80 & 1.5 & 34.0 \\
\hline 7 & Kerala & 17.90 & 14.70 & 13.90 & 5.6 & 6.9 & 6.9 & 14.0 & 12.0 & 7.0 & 4.00 & -1.3 & 7.0 \\
\hline 8 & Madhya Pradesh (MP) & 31.40 & 26.30 & 24.60 & 10.3 & 8.0 & 6.7 & 87.0 & 54.0 & 48.0 & 6.80 & 3.6 & 39.0 \\
\hline 9 & Maharashtra & 21.00 & 16.50 & 15.60 & 7.5 & 6.2 & 5.5 & 48.0 & 24.0 & 19.0 & 5.40 & 2.0 & 29.0 \\
\hline 10 & Orissa & 24.30 & 19.60 & 18.20 & 10.5 & 8.4 & 7.3 & 95.0 & 51.0 & 40.0 & 6.10 & 3.2 & 55.0 \\
\hline 11 & Punjab & 21.60 & 15.70 & 14.80 & 7.4 & 6.7 & 6.6 & 52.0 & 26.0 & 20.0 & 6.80 & 0.8 & 32.0 \\
\hline 12 & Himachal Pradesh (HP) & 22.10 & 16.00 & 15.70 & 7.2 & 6.7 & 6.9 & 60.0 & 35.0 & 19.0 & 6.40 & 0.3 & 41.0 \\
\hline 13 & $\begin{array}{l}\text { Jammu \& Kashmir and } \\
\text { Ladakh (J\&K) }\end{array}$ & 19.70 & 17.50 & 15.40 & 6.2 & 5.3 & 4.9 & 50.0 & 37.0 & 22.0 & 4.30 & 1.3 & 28.0 \\
\hline 14 & Delhi & 20.30 & 17.20 & 14.70 & 5.1 & 4.1 & 3.3 & 32.0 & 24.0 & 13.0 & 5.60 & 1.8 & 19.0 \\
\hline 15 & Chhattisgarh & 26.70 & 24.40 & 22.50 & 9.6 & 7.9 & 8.0 & 79.0 & 46.0 & 41.0 & 4.20 & 1.6 & 38.0 \\
\hline 16 & Jharkhand & 26.50 & 24.60 & 22.60 & 9.0 & 6.8 & 5.4 & 70.0 & 37.0 & 30.0 & 3.90 & 3.6 & 40.0 \\
\hline 17 & Uttaranchal & 20.20 & 18.20 & 16.70 & 6.9 & 6.1 & 6.2 & 50.0 & 32.0 & 31.0 & 3.50 & 0.7 & 19.0 \\
\hline 18 & Rajasthan & 31.40 & 25.60 & 24.00 & 8.5 & 6.5 & 5.9 & 79.0 & 47.0 & 37.0 & 7.40 & 2.6 & 42.0 \\
\hline 19 & Tamil Nadu (TN) & 19.30 & 15.60 & 14.70 & 7.9 & 7.3 & 6.5 & 51.0 & 21.0 & 15.0 & 4.60 & 1.4 & 36.0 \\
\hline 20 & Uttar Pradesh (UP) & 32.80 & 27.20 & 25.60 & 10.3 & 7.7 & 6.6 & 83.0 & 50.0 & 43.0 & 7.20 & 3.7 & 40.0 \\
\hline \multirow[t]{2}{*}{21} & West Bengal (WB) & 20.70 & 16.00 & 15.00 & 7.0 & 7.0 & 5.6 & 51.0 & 31.0 & 22.0 & 5.70 & 1.4 & 29.0 \\
\hline & All India & 25.80 & 21.40 & 20.00 & 7.8 & 7.0 & 6.2 & 68.0 & 40.0 & 32.0 & 5.80 & 1.6 & 36.0 \\
\hline
\end{tabular}

Sources: SRS Bulletin, 2000 data published October 2001, Vol-35, No-2, 2013 data published in September 2014, Vol.19, No-1 and 2018 data published in May 2020, Vol-53, No-1.

\subsection{Regional inequality in crude birth rate}

CBR refers to the number of births over a given period divided by the person-years lived by the population over that period. It is expressed as number of births per 1,000 populations. Birth Rate is calculated as the number of live births in a year per 1,000 of the mid-year population. CBR is called "crude" because it does not consider age or sex differences among the population. CBR shows the fertility rate and population growth in a country. Table 1 reveals the CBR in the world and India is 19 per 1,000 population. It leads to faster population growth and stress on available resources. After the independence governments have been trying to put check on fast population growth but it continues to be a serious problem in developing countries like India. Regional disparity in CBR can be seen in the world. It is 19 in India which is equal to the world average. It is more than 10 in developed countries like USA, China, UK, Russia and Canada whereas Japan, Singapore and Germany have less than 10.

Table 2 reveals the disparity of crude birth rate among major states of the country during 2000-2018. All India average birth rate was 20 per a thousand births in 2018. The highest percentage of such rate being in Bihar (26.2) followed by UP (25.60), MP (24.60) and Rajasthan (24), Assam (22.4) and Haryana (21.3). Remaining 11 states of these 21 major states had percentage lower than the National average. Comparatively richer states have CBR below than the national average. It supports the view that economic development is the best contraceptive to check fast population growth. Again, the figure in Kerala is the lowest at 13.9 in 2018 whereas poorer states like, MP, UP, Assam, Jharkhand, Chhattisgarh, Rajasthan, and Bihar exceed the national average. Rural urban disparity also noticed in every major states. 
National average of rural India birth rate is 21.60 and urban 16.70 per 1,000 populations. Regional inequality can be seen in Table 1. The birth rate falls sharply on account of universal literacy, spread of female literacy, and extensive use of family planning devices and high level of living. One emerging trend is that women are more likely to enter in the global as well as domestic labour market. This is also a reason for falling the Birth rate in this country.

\subsection{Regional inequality of crude death rate}

CDR refers to the number of deaths over a given period divided by the person-years lived by the population over that period. It is expressed as number of deaths per 1,000 populations The Crude Death Rate is defined as the number of deaths in a year per 1,000 of the midyear population. Table 1 reveals the disparity of crude death rate among some developed and developing countries. The world CDR average has come down to 7.54 due to economic development and better medical facilities. There are lesser numbers of deaths in countries like India, China, Singapore, whereas even some developed nations including Japan, Germany, Canada, Russia, UK, and USA witness more deaths than the world average at 7.54 .

Table 2 reveals the inequality of crude death rate among major states of country during 2000-2018. All India average birth rate was 21.4 per a thousand births in 2013. The highest percentage of such rate being in Bihar (27.6) followed by UP (27.25), MP (26.3) and Rajasthan (25.6), Assam (22.4) and Haryana (21.3) (Kumar \& Singh, 2015). All India CDR declined from 14.9 per thousand death in 1971 to 6.2 in 2018. The highest death rate being in Chhattisgarh (8.0), followed by Orissa (7.3), Kerala and HP both (6.9), MP (6.7), UP and Punjab (6.6), TN (6.5). Uttaranchal and Karnataka are close to National Average. Remaining states of these 21 major states had percentage lower than the National average. Inter-state variations are also noticeable. Comparatively richer states have CDR below than the national average. Again, the data in poorer states likes Orissa, MP, UP, and Assam exceeds the national average. These poorer states provide very poor health facilities to their population. Death rate of rural is higher than that in the urban. In year 2018 the rural death rate was 6.7, whereas that of urban was around 5.1. Death rate falls because of the superfluity of young population and better health infrastructure available in the urban area. Regional inequality of CDR can be seen in Table 2.

\subsection{Inequality in infant mortality rate}

IMR is defined as the number of infants dying in a year per 1,000 live births during the year. It is calculated as a ratio of the number of deaths among the 1,000 born children before they celebrate their first birthday. IMR is the indicator of health care for the newborn babies. It is incredibly sad to see that there are more deaths of infants despite tremendous economic growth, launching of immunization programmes world over and medical facilities. Needless to say, the high infant mortality is due to inadequate prenatal and post-natal care of mothers, inadequate childcare, malnutrition in poorer section of population etc. Huge disparity is witnessed in the world so far as the infant mortality is concerned. It is 35.4 in India and that is quite higher and alarming than that of the world average at 29.26. The IMR in developed countries like Japan, Singapore, Germany, Canada, and UK have infant mortality rate less than 5, whereas India, Brazil and China witness more than 10 infant deaths per 1,000 population. India's figure of 35.4 is alarming. It is a matter of great concern for policy makers who have failed to deliver adequate public health. In India, several steps have been taken by governments like integrated child development services (ICDS), mid-day meal, massive immunization, and safe delivery but more steps need to be taken. Infant mortality for black babies remains nearly 2.5 times higher than for white babies (Wayne, 2012).

Table 2 reveals the inequality of infant mortality rate among major states of the country during 2000-2018. IMR was reported to be 68 per 1,000 live births in 2,000 and now it has reduced to 32 per 1,000 live births in 2018. The main causes of deaths are diseases of circulatory system, infections and parasitic diseases, injury, poisoning, poor pre-natal conditions, and diseases of respiratory system. The main constraints are low literacy and lower income levels, sociocultural beliefs and practices, and sub optimal utilization of health facilities. The infant mortality rate is also called the infant death rate.

There is a wide regional inequality in infant mortality rates. All India average IMR was 32 per a thousand births in 2018. The highest percentage of such rate being in MP (48) followed by UP (43) Assam and Chhattisgarh both (41), Orissa (40), Rajasthan (37), Gujarat and Haryana (33). Bihar is around the National Average. Remaining states of these 
21 major states had percentage lower than the National average. Comparatively richer states have IMR below than the national average. Again, the figure in Kerala is the lowest at 7 per thousand births in 2018 whereas poorer states like Orissa, MP, UP, Assam, Bihar exceed the national average. In MP estimated IMR is 7 times higher than that in Kerala. Needless to say, these poorer states provide very poor health facilities to their population. Details can be seen Table 1 .

The infant mortality rate in India is steadily decreasing. Children whose mothers have no proper education are more than twice as likely to die before their first birthday as children whose mothers have completed at least 10 years of schooling. High of infant deaths in rural areas are directly or indirectly related to maternal/child malnutrition, viz., Prematurity (30\%), Pneumonia (14.5\%), Respiratory Infection (11\%), Anemia (2.9\%), Diarrhea (2.9\%) and unsafe delivery practices (Rao \& Choudhury, 2008).

\subsection{Inequality in life expectancy}

No doubt, there has been continuous rise in the life expectancy in both the developed and developing countries due to economic growth, check on many communicable and non-communicable diseases and better medical facilities across the world in the post-world war period. But here also wide disparity can be notice between developed and developing countries. On an average, the world life expectancy has rose to 73.2 years. In Japan and Singapore, life expectancy is 85.3 and 84.7 years respectively but India, Brazil, Russia, and USA have less than 80. Global inequality of life expectancy among some developed and developing countries can see in Table 1.

India has made substantial progress in terms of health indicators over the past few decades. Life expectancy of India increased from 54 years in 1980, 66 years in 2013 to 69 years in 2012-2016. This increase in life expectancy is the result of an overall decline in mortality. Japan has the highest life expectancy in the world and on average Japanese is expected to live 83 years. Higher life expectancy contributes to economic growth more than education. This is obvious as higher life expectancy means sound health, better physical strength and lesser man days' loss due to illness. State wise inequality of Life Expectancy in India 2012-2016 can be seen in Figure 1.

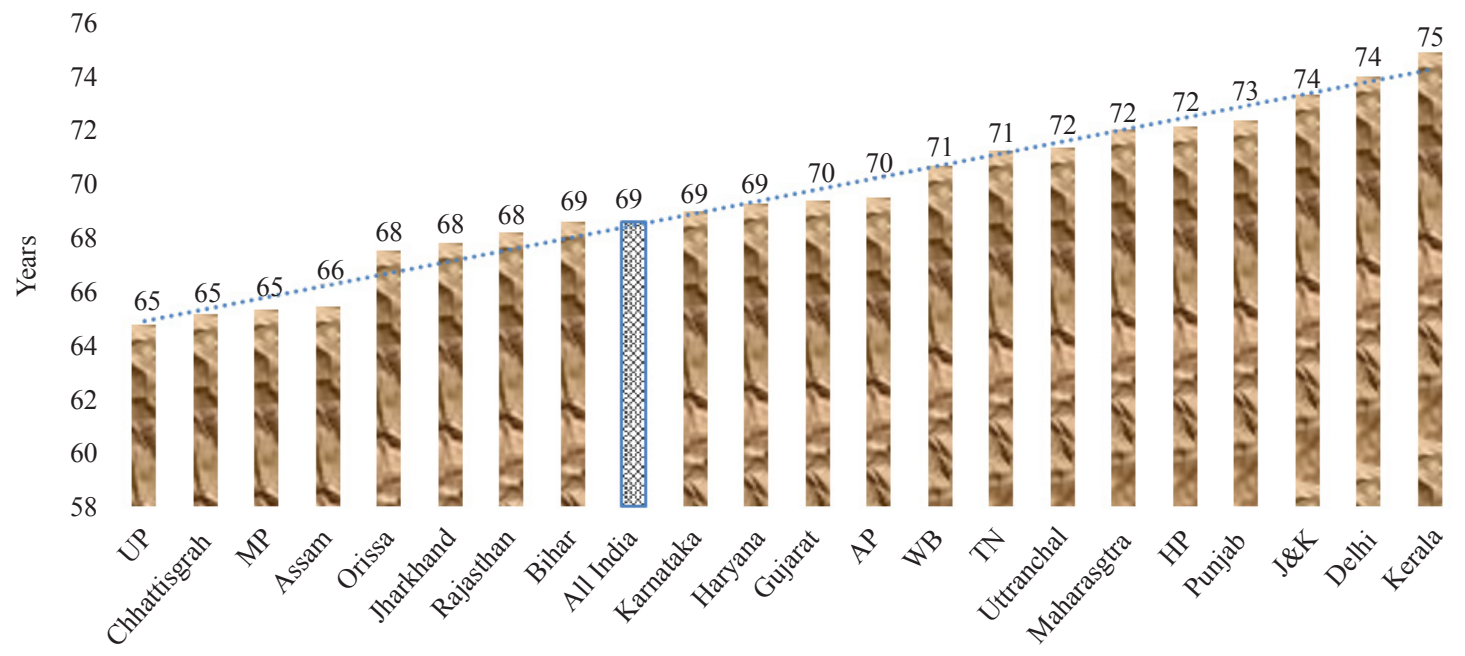

Source: MOHFW (2019).

Figure 1. State wise average life expectancy 2012-2016

Life expectancy at birth has increased from 62.6 years for males and 64.2 years for females (2002-2006 India as 67.4 years for males and 70.2 years for females in years 2012-2016). National average is 69 years. This has revealed the decrease in death rate and the better improvement of quantity and quality of health services in India. In Kerala, a person at birth is expected to live for 75 years while in states like Assam, Madhya Pradesh, Uttar Pradesh, Chhattisgarh, Orissa, etc., the expectancy is in the below than national average. Bihar and Rajasthan both are near the national average. Figure 2 reveals the male-to-female inequality of life expectancy among major states of country during 2012-2016. 


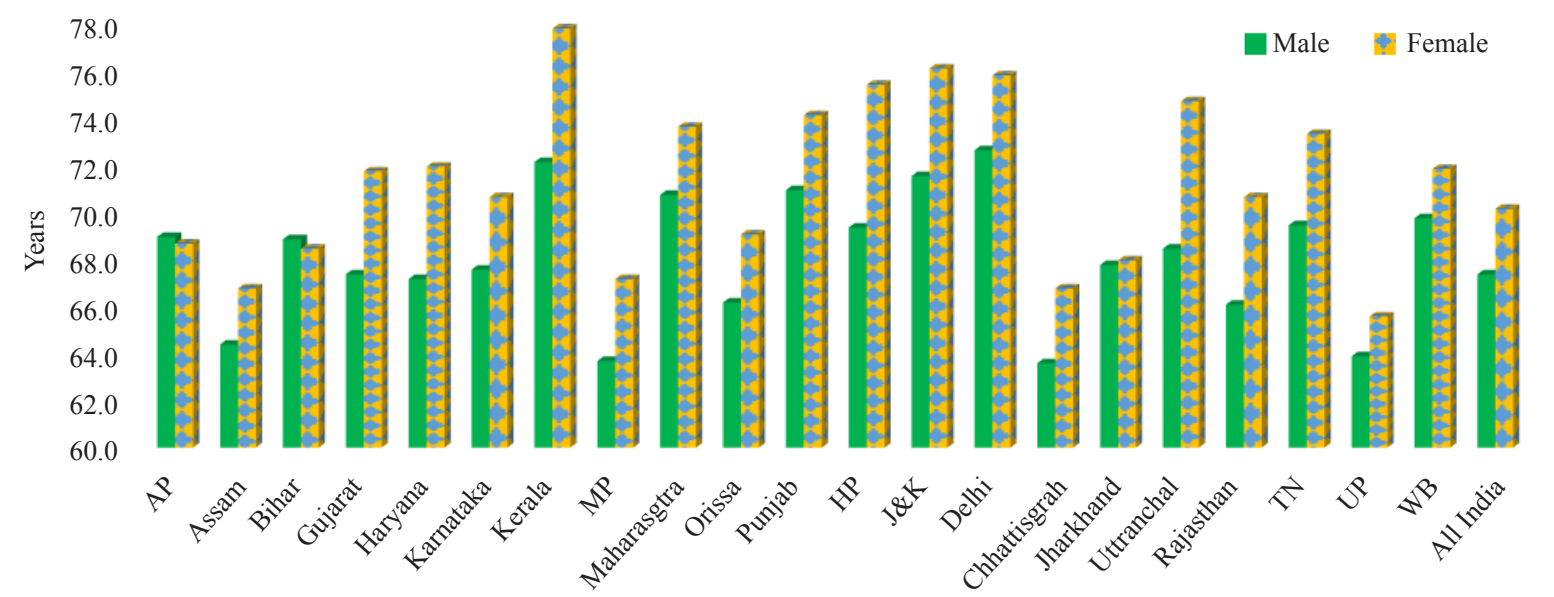

Source: Sample Registration System, Bulletin, various issues, Office of the Registrar General and Census Commissioner, Ministry of Home Affairs, Government of India.

Figure 2. State wise male female disparity of life expectancy in India 2012-2016

All India average life expectancy was 67.4 for males and 70.2 years for females in 2012-2016. The highest percentage of such rate being in Kerala (75.1 years) followed by Delhi 74.2, J\&K 73.5, Punjab 72.5 years, HP 72.3 years, Maharashtra (72.2 years), TN 71.4 years, and Haryana 69.4 years. Karnataka and Bihar are near to National Average. Remaining 6 states of these 21 Major states average life expectancy was lower than that of the National average. The regional inequality is also noticeable in Figure 2. Comparatively richer states have LE above the national average. Again, the figure in Kerala is the highest at 75.1 years in 2012-2016, whereas poorer states like Orissa, MP, UP, Assam have below the national average. However, there are inter-state rural-urban differences in life expectancy at birth due to low literacy, differential income levels and socio-economic conditions and beliefs. One noticeable fact is that there is difference in life expectancy on the basis of sex also. But that goes in favor of females in most of the states and at all India level.

\subsection{Inequality maternal mortality ratio}

Maternal mortality in India is the maternal death of a woman during pregnancy or after pregnancy, including post-abortion or post-birth periods. MMR defined as the number of maternal deaths per 100,000 live births. MMR is calculated as maternal deaths to women in the ages 15-49 per lakh of women in that age group. World Health Organization, maternal death is the death of a woman while pregnant or within 42 days of termination of pregnancy, from any cause related to or aggravated by the pregnancy or its management. United Nations aims to reduce the global maternal mortality ratio to less than 70 per 100,000 live births in Sustainable Development Goals. Only five states in India (Kerala, Maharashtra, Tamil Nadu, and Andhra Pradesh) have achieved the Sustainable Development Goal of reducing the MMR below 70. Figure 3 reveals the Inequality of maternal mortality rate and maternal mortality ratio among major states of the country during 2016-2018.

According to United Nations International Children's Emergence Fund (UNICEF), the major causes of maternal deaths are severe bleeding, infections, high blood pressure during pregnancy, and complications from delivery and unsafe abortions. As per National Family Health Survey-IV around 78.9 per cent of births are in health care institutions in 2015-2016 so MMR is gradually reducing. Assam had the highest MMR (215) in the country, followed by Uttar Pradesh and Madhya Pradesh with MMR of 197 and 173. Rajasthan, Uttar Pradesh, and Odisha have recorded the highest decline in MMR. Kerala (43), Maharashtra (46), Tamil Nadu (60), Andhra Pradesh (65), Jharkhand (71), Gujarat (75), Haryana (91), Karnataka (92), West Bengal (98) and Uttarakhand (99) have met the National Health Policy target of reducing the maternal mortality ratio to 100 . 


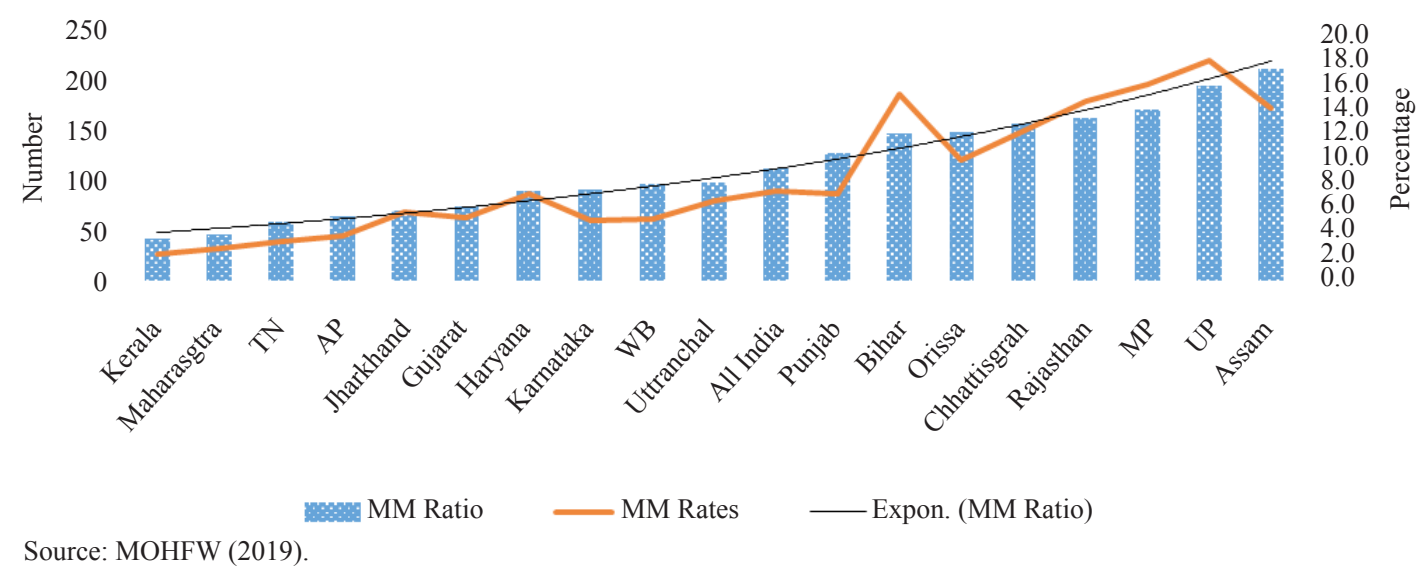

Figure 3. State wise Maternal Mortality Ratio and Maternal Mortality Rates in 2016-2018

\section{Inequality of expenditure on health sector}

Health expenditure includes all expenditure whose primary purpose is to restore, improve and maintain health for nation and for individuals during a defined period (WHO, World Bank \& USAID, 2003). World Health Organization defines health systems as "all the activities whose primary purpose is to promote, restore, or maintain health" (WHO, 2001). The share of public expenditure as a percentage to GDP on health and education at higher level has been gradually declining. Expenditure on education improves skill and productivity of individuals, expenditure on health and medical services result in promoting reduction in death rate or birth rates and "primarily affect the numbers and secondly the skill capacity and efficiency" (Kothari, 1996). A number of studies using a demand function approach found a strong and positive relationship between national income and health care expenditure (Kleiman, 1974; Lev, 1986; Hitiris \& Posnett, 1992; Pritchett \& Summers, 1996). Several studies (MOHFW, 2005; Barman et al., 2010; Peters et al., 2002) have indicated the government health expenditures do indeed affect health outcomes. However, government spending in our country has consistently remained very low. Rao and Choudhury (2008) have suggested equalizing transfers to ensure minimum standards of expenditure on health care in all the states. This study indicates that the five states of Bihar, UP, MP, Rajasthan and Orissa are the states with low income and low health achievement.

Percentage of GDP spent on public health shows the priority of the government policy and the affordability on health care. For better health there is need of health infrastructure, a greater number of doctors, nursing staff and other health workers as well as R\&D in medicine. That requires huge expenses which poorer countries cannot afford. The world average of expenditure on health is 9.88 per cent of GDP but wide disparity can be seen between developed and developing nations in Table 1. USA spends 17.06 per cent of its GDP on health, followed by Germany (11.25\%), Japan (10.94\%), and Canada (10.57\%) share of GDP. On the other hand, Russia, Brazil, China, and Singapore allocate less than 10 per cent of its GDP on health services. The share of GDP being spent in India is too low to provide even the basic health care to the people. It is just 3.53 per cent of GDP which is inadequate to provide better hospitals, enough doctors, nurses, and other health workers. Due to paucity of fund, pharmaceutical research is also not possible. The record it is high time the developing countries must focus on health sector. Table 3 reveals the disparity of total health expenditure and government health expenditure, per capita expenditure on health among major states of country during year 2001-2002 and 2016-2017. Annual per capita expenditure on health during 15 years also reveals in above table. Annual per capita expenditure on health highest in Haryana (2.31\%), followed by Bihar (2.20\%), UP (2.16\%) and MP $(2.02 \%)$. Another side noticed in above table that lowest annual growth rate during last 15 years (2001-2002 to 20162017) was Karnataka $(0.92 \%)$ followed by Orissa $(0.96 \%)$. 
Table 3. State wise Health Expenditure in India 2016-2017

\begin{tabular}{|c|c|c|c|c|c|c|c|c|c|}
\hline \multirow{2}{*}{$\begin{array}{l}\text { Sr. } \\
\text { No. }\end{array}$} & \multirow{2}{*}{ States } & \multirow{2}{*}{$\begin{array}{c}\text { Per capita } \\
\text { total health } \\
\text { expenditure in } \\
2001-2002(\mathrm{Rs})^{*}\end{array}$} & \multicolumn{3}{|c|}{$\begin{array}{l}\text { Total Health Expenditure (THE) } \\
\text { 2016-2017 }\end{array}$} & \multicolumn{4}{|c|}{ Government Health Expenditure (GHE) } \\
\hline & & & Rs. Crore & $\begin{array}{l}\text { Per capita } \\
\text { (Rs) }\end{array}$ & $\%$ GSDP & Rs. Crore & $\%$ GHE & $\begin{array}{l}\text { Per capita } \\
\text { (Rs) }\end{array}$ & $\%$ GSDP \\
\hline 1 & $\mathrm{AP}$ & 1,039 & 28,981 & 4,600 & 4.2 & 7,090 & 24.5 & 1,125 & 1.0 \\
\hline 2 & Assam & 569 & 8,453 & 2,562 & 3.3 & 3,294 & 39 & 998 & 1.3 \\
\hline 3 & Bihar & 779 & 26,885 & 2,358 & 6.4 & 5,740 & 21.3 & 504 & 1.4 \\
\hline 4 & Gujarat & 816 & 23,700 & 3,703 & 2.1 & 9,145 & 33.9 & 1,237 & 1.4 \\
\hline 5 & Haryana & 1,570 & 12,238 & 4,533 & 2.2 & 3,621 & 29.6 & 1,341 & 0.7 \\
\hline 6 & Karnataka & 712 & 34,210 & 5,183 & 2.8 & 9,168 & 26.8 & 1,389 & 0.8 \\
\hline 7 & Kerala & 1,858 & 28,291 & 8,083 & 4.5 & 7,522 & 26.6 & 2,149 & 1.2 \\
\hline 8 & MP & 864 & 21,999 & 2,820 & 3.4 & 6,324 & 28.7 & 811 & 1.0 \\
\hline 9 & Maharashtra & 1,011 & 63,046 & 5,210 & 2.9 & 14,708 & 23.3 & 1,216 & 0.7 \\
\hline 10 & Orissa & 582 & 18,266 & 4,059 & 4.6 & 4,988 & 27.3 & 1,108 & 1.3 \\
\hline 11 & Punjab & 1,530 & 17,285 & 5,960 & 4.0 & 3,421 & 19.8 & 1,180 & 0.8 \\
\hline 12 & HP & 1,305 & 3,851 & 5,501 & 3.1 & 1,971 & 51.2 & 2,816 & 1.6 \\
\hline 13 & $\mathrm{~J} \& \mathrm{~K}$ & NA & 5,138 & 3,952 & 3.5 & 1,995 & 38.8 & 1,535 & 1.6 \\
\hline 14 & Chhattisgarh & NA & 10,214 & 3,648 & 4.0 & 3,463 & 33.9 & 1,237 & 1.4 \\
\hline 15 & Jharkhand & NA & 8,325 & 2,313 & 3.5 & 2,582 & 31.1 & 717 & 1.4 \\
\hline 16 & Uttaranchal & NA & 4,421 & 4,019 & 2.3 & 1,596 & 36.1 & 1,450 & 0.8 \\
\hline 17 & Rajasthan & 559 & 25,592 & 3,412 & 3.4 & 8,447 & 33 & 1,126 & 1.1 \\
\hline 18 & $\mathrm{TN}$ & 846 & 36,451 & 4,734 & 2.8 & 9,959 & 27.3 & 1,293 & 0.8 \\
\hline 19 & UP & 1,124 & 75,634 & 3,469 & 6.1 & 16,828 & 22.2 & 772 & 1.3 \\
\hline 20 & WB & 775 & 41,059 & 4,277 & 4.7 & 8,697 & 21.2 & 906 & 1.0 \\
\hline
\end{tabular}

Sources: Computed from National Health Accounts Estimate 2016-2017, Ministry of Health and Family Welfare, Government of India National Health Accounts 2002-2003, Ministry of Health and Family Welfare, Government of India.

Diagram-4 reveals the disparity of per capita expenditure on health among major states of country during 20162017. Total expense on health sector in Bihar 6.4 per cent of gross state domestic products (GSDP) while Gujarat only 2.1 per cent of GSDP.

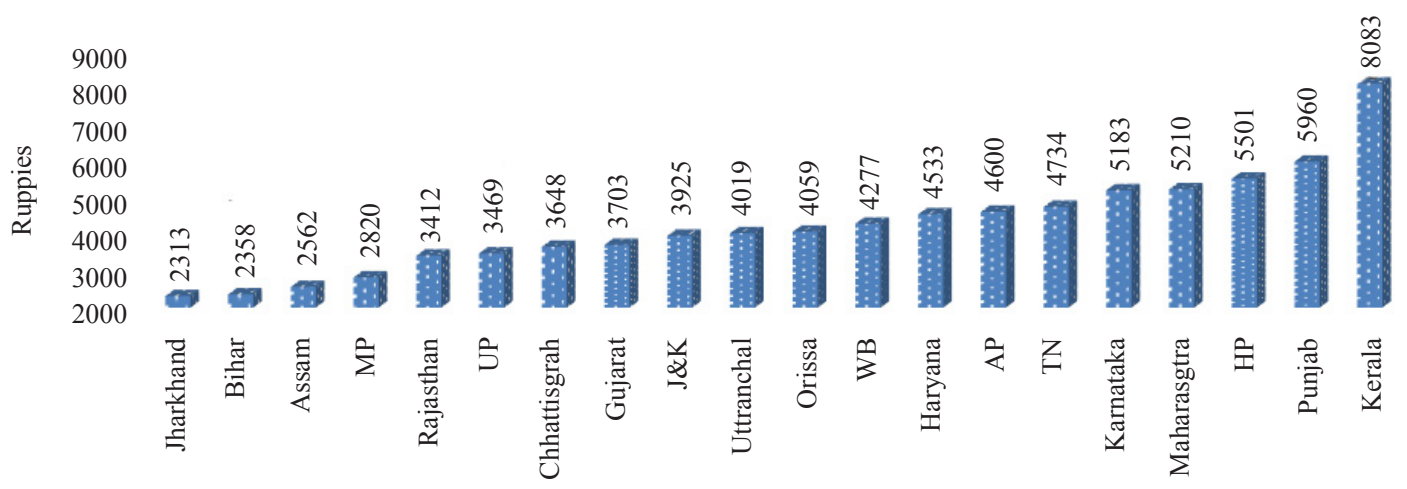

Figure 4. State wise Per capita Expenditure in 2016-2017

The per capita health expenditure of major states for the year 2016-2017 indicated that the level of public health 
spending has been relatively higher in the states of HP, Punjab, and Kerala while lower in UP, Bihar, MP, and Orissa. Private expenditure was higher in Kerala, Assam, J\&K, and Gujarat as compared to Punjab, WB, and Bihar and UP. Per capita health spending in Kerala was the highest while in Jharkhand it was the lowest. Across the country it can easily be seen that expenditure on health care is a primary cause of indebtedness. Due to inadequate and non-performing public health infrastructure, the poor are forced to go to private doctors who charge the exorbitant fee.

The 2021-2022 Budget of Government of India gives special attention on health and well-being of 1,300 million citizens. An estimated fund allocation of 233,000 crore has been made on public health expenditure. It is 137 per cent increase over previous year health budget. 70,000 crores will be spent to improve health infrastructure in 4,378 urban centres. 300 health units, 12 central institutions, 15 health emergency units, 2 mobile hospitals, 9 laboratories and 4 more national laboratories will be set up and developed. Special nutrition drive will be launched in 112 districts across the nation. JAl Mission Yojana with 2.87 lakh crores will be spent to improve health infrastructure in 4,378 urban local bodies in coming 5 years. 1.41 lakh crores will be spent on 'Swaksh Bharat, Swastha Bharat Mission' in next 5 years period. For clean air in 48 million plus cities, Rs. 2,217 crores is to be spent. Rs. 64,180 crores are allocated for Aatma Nirbhar Swaksha Bharat Yojana over the period of 6 years. The idea is to develop capacities of health care system, to develop institutions and to detect and cure the new and emerging diseases. Under this plan 17,000 rural and 11,000 urban wellness centers will be created. All these plans and schemes are in addition to National Health Mission and PMJan Arogya Yojana for which 33,400 crore and 6,400 crores respectively is allocated in this budget.

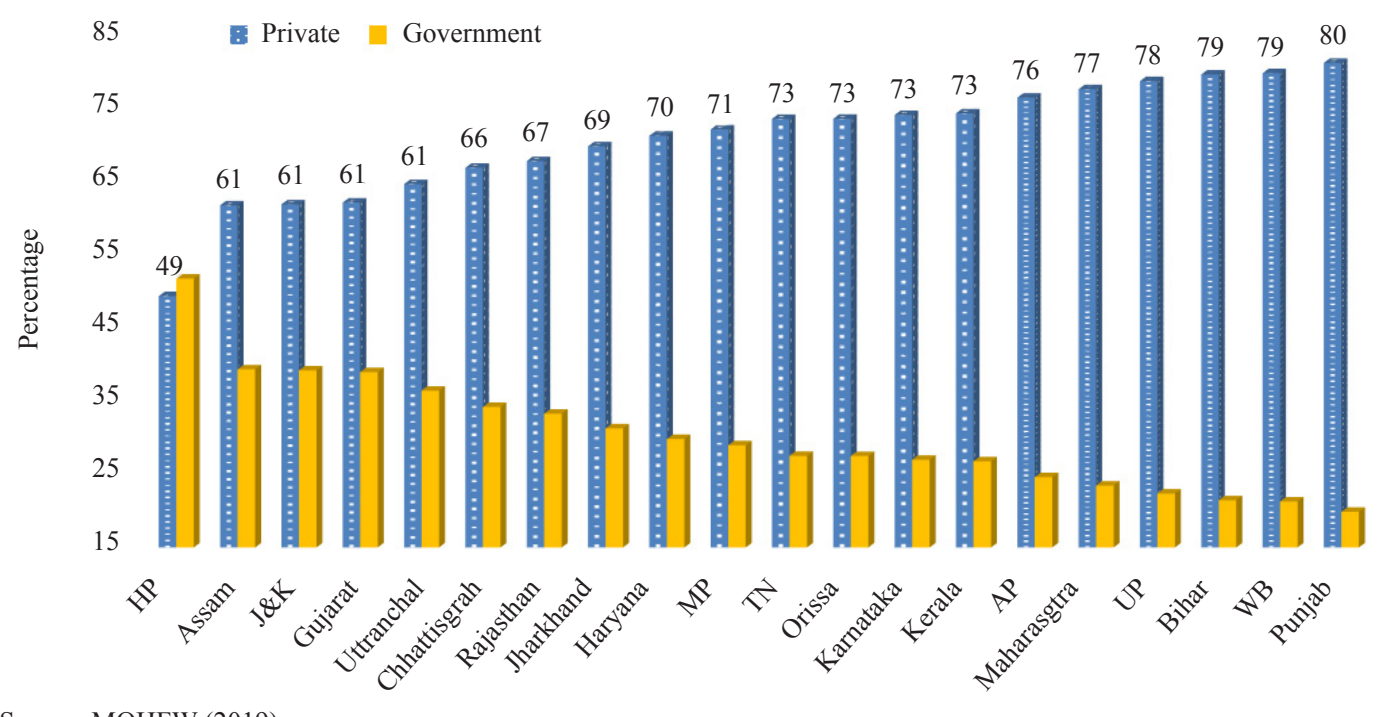

Source: MOHFW (2019).

Figure 5. Share of Public Private Health Expenditure in Major States 2016-2017

The private and public expenditure in states has been presented in Figure 5. Private expenditure on health sector in Punjab during 2016-2017 was around 80 per cent, only 20 per cent by the public sector.

\section{Health infrastructure}

Health Infrastructure is an important indicator to understand the healthcare delivery provisions and mechanisms in a country. Infrastructure for dispensing health related services require improvements. Health infrastructure is the also included with the availability of health personnel-doctors, nurses, auxiliary nurse-cum-midwife (ANM), and accredited social health activist (ASHA). Number of registered Allopathic Doctors in 2008 was 84,852, which increased and reached on 114,969 in year 2018. This is 35 percent increased during last ten years. During same period AYUSH Doctors includes Ayurveda, Unani, Siddha, Naturopathy, and Homeopathy was 751,926 in 2008 has been a 
steady increase in the 773,668 in 2018. Total number of Nurses and Pharmacists were 2,254,055 in 2008 which rapidly increased 3,785,494 in year 2018. This is around 68 per cent increased during same period (MOHFW, 2018). There are 23,582 hospitals having 700,761 beds in the country. 19,810 hospitals are in rural area with 279,588 beds and 3,772 hospital are in urban areas with 431,173 beds in year 2018.

Table 5. Number of hospitals and beds in india

\begin{tabular}{cccc}
\hline Sr. No. & Organization & Hospitals & Beds \\
\hline 1 & Government Hospitals (2018) & 23,582 & 700,761 \\
2 & AYUSH (2017) & 3,893 & 53,026 \\
3 & CGHS (2017) & 50 & 2,216 \\
4 & Ministry of Defense & 133 & 34,520 \\
5 & Railways (as on 21/03/2018) & 126 & 13,748 \\
6 & Employees State Insurance Corporation (2017) & 151 & 19,765 \\
\hline
\end{tabular}

Source: National Health Profile 2018.

Note: Computed from Minister of State (Health and Family Welfare), Shri Ashwini Kumar Choubey stated this in a written reply in the Rajya Sabha.

Primary health infrastructure in rural areas consists of a three-tier system. This includes sub-centers (SCs), primary health centers (PHCs), and community health centers (CHCs). One sub center has a trained female health worker and a male health worker for a population of 5,000 in the plains and for a population of 3,000 in hilly and tribal areas. One primary health center (PHC) is staffed by a medical officer and other paramedical staff for a population of 30,000 in the plains and a population of 20,000 in hilly, tribal and backward areas. A PHC supervises six sub-centres. As of 2018, Numbers of PHCs 29,899, CHCs 5,568, SDH 1,255 and DH 1,003. There is a shortage of 2,188 CHCs, 6,430 PHCs and $32,900 \mathrm{SCs}$.

\section{Challenges in health sector}

COVID 19 is the biggest and challenge in front of this sector. The coronavirus pandemic has created challenges in virtually every aspect of business and human habitation. No portion of the world is left untouched from this outbreak. It can without any hesitation be termed as the most horrible pandemic of the century which has compelled the people to keep themselves in the house arrest like situation, that too without much financial and mental security. It has created a sense of helplessness, frustration, and mental emotional vacuum among the professionals. Many professionals have committed suicide and ruined their lives. The youth is become directionless. The young students are locked in their houses and miss the taste, fragrance, charm, and democratic taste of classroom culture. The teachers are missing their students and direct response and feedback from their students. The world civilizations are socially, emotionally and psychologically broken. The domestic violence is at rise everywhere. Wives, women, and children are beaten, illtreated and tortured. There is a serious threat that this pandemic may increase 4 to 5 crore populations of the world. The doctors and paramedical staffers are killed due to the COVID 19. The financial and industrial growth is almost stopped. The skilled, semi-skilled and unskilled laborer are jobless. The number of inbound laborers has created big problem in various poor states of India. Communicable diseases such as Malaria, Tuberculosis, and Japanese Encephalitis, Dengue, Chikenguania Ebola virus, Hepatitis-C, are also the biggest challenges being faced by the country. They are going to trouble us in the near future too. Non-communicable diseases are becoming a major public health problem in the country due to changing lifestyles, increasing stress and tensions. Food insecurity and under nutrition are also an important challenge for health sector in this country. National Family 53 per cent women and 23 per cent men aged 1549 had anemia, and around 305 persons per 100,000 had medically treated tuberculosis. The prevalence of tuberculosis was higher among women (389 per 100,000) than among men (220 per 100,000) (NFHS, 2015). Forty-three per cent of Indian children under five years are underweight and 48 per cent (i.e. 61 million children) are stunted due to chronic under nutrition, India accounts for more than 3 out of every 10 stunted children in the world. 
Rural health care in most states is marked by absenteeism of doctors, health providers, nurses, para medical staffs, low levels of skill, shortage of medicines, inadequate supervision and monitoring etc. There are neither rewards for service providers nor punishments for defaulters, as a result health outcome in India are adverse compared to the bordering countries and South East Asian Countries. The shortage of Doctors and other Para-medical staff, the ratio of nurses to doctors is also below the optimum, lack of paramedical personnel. Other constraints include the low priority given to in-service training, inadequate staffing of training institutions, quality concerns among trainers, and inadequate facilities in training institutions in the health sector.

The people from rural areas have to travel long distance for the treatment of major disease. Many of them find it difficult for financial and other reasons. There is a dearth of public sector hospitals with state-of-art facilities. Treatment in private hospitals is so expensive that it is beyond the reach of majority of rural population. The much-popularized Nehru Rural Health Mission (NRHM) has not achieved the objective due to several reasons including mal practices, corruption and ghotalas or scams. All these facts should be kept in mind while making plans and their implementations for achieving the goal of health for all in future.

\section{Health sector policy}

Health is an important aspect of human development index. It is essential not only for longevity and happy living but also for productivity and economic growth. The government has taken several initiatives to promote health status of the people. All these government Schemes and Programmes are designed to serve the great purpose of promoting health of the people. But success of these programmes depends upon the sincerity and honesty in their execution. For achieving the goal of inclusive growth in health sector, there is need of good governance for the execution of various health sachems and programme launched by the government.

Pradhan Mantri Jan Arogya Yojana (PMJAY) launched in September 2018 under the Ayushman Bharat programme, PMJAY aims to provide a cover of Rs five lakh per family per year to 10.7 crore families (no cap on family size and age) belonging to poor and vulnerable population. The scheme subsumed two centrally sponsored schemes, namely, Rashtriya Swasthya Bima Yojana (RSBY) and the Senior Citizen Health Insurance Scheme. The scheme provides insurance coverage for secondary and tertiary healthcare. At present, 1,393 procedures across different specialties such as general medicine, oncology, cardiology, and orthopedics are covered. In addition, the scheme provides for pre and post hospitalization expenses.

In 2020-2021, PMJAY has been allocated Rs 6,400 crore, an increase of 100 per cent over the revised estimates of 2019-2020. In 2019-2020, the scheme was allocated Rs 6,400 crore which was revised downward to Rs 3,200 crore (MOHFW, 2020). In last few years, Government of India has been launching missions and schemes to provide better health infrastructure and health care services to citizens, especially the weaker section. In last one year, COVID 19 pandemic has not only posed big challenge on health but also on the world economy. India fought the pandemic with firm determination, concrete plans and missionary zeal. Amid the unprecedented crisis in the post-world war period, caused by COVID 19 pandemics, India's Finance Minister proposed the 2021-2022 budget in the Lower House of the Parliament. She prepared the budget under the visionary leadership of PM who has given clarion call for 'Aatma Nirbhar Bharat' (the self-reliant India). The budgetary edifice rests on 6 pillars. Health and wellbeing is one of those 6 strong pillars.

India's budget (2021-2022) reflects deep imprint of COVID 19 induced global pandemic. The budget allocates 35,000 crores for development and application of COVID 19 vaccine. Government of India works on the ideal of 'Sarve Santu Niramaya' (healthy life for entire humanity). India is using 2 vaccines not only for Indian citizens but also offering liberally to neighboring and other countries. 4 more vaccines are expected shortly. The plans and increased fund allocation will, certainly have better implications on health and well-being of the people. It will have good impacts on various health indicators like death rate, mortality rate, infant mortality rate, life expectancy etc. The improved health care system will reduce the financial burden on common people. 


\section{Conclusion}

A careful examination of the available data makes it clear that the inequality and disparity of health practices, health status, health culture and health infrastructure are clearly visible in India. We are the extraordinary mix of most educated and most illiterate; well off and the poorest; densely populated and sparsely populated states. Unity in diversity is exhibited in every sphere of life and habitation. Probably due to lack of strong decision-making ability and leadership crisis, we have failed to correct various regional disparities of India. To start with we can take the example of south Indian state Kerala. One noticeable fact is that Kerala's is a better performing state with all health indicators, high health awareness and its excellent health status despite the fact that per-capita GSDP and per capita health expenditure in Kerala is lower than some states (Kumar, 2006). Public expenditure on health still remains low and needs to be substantially increased to make an impact on various health indicators. The problem of shortage of Doctors and other Para-medical staff and their absenteeism has to be sorted out. It is not just the deficiency of doctors and paramedical staff but also their willingness to serve in rural and inaccessible areas. The government has also to make effort to provide necessary civil and other infrastructure for medical personnel to serve there. Rural sanitation, safe drinking water, vaccinations and immunizations institutional delivery, various preventive measures and awareness campaigns are essential for preventing the health hazards. Traditional and low-cost Indian system of medicine like Ayurveda, Naturopathy and Unani should be encouraged and improvised to increase their acceptability by the masses. Yoga should be popularized with the help of trained and certified Yoga teachers. There is a need to take timely proactive steps to improve the health of population which will lead to the good health of economy of the nation. Developed and strong nation needs healthy citizens.

\section{References}

Adena, M., \& Myck, M. (2014). Poverty and transitions in health in later life. Social Science \& Medicine, 116, $202-210$.

Barman, P., Ahuja, R., \& Bhandari, L. (2010). The improving effect of healthcare payment in India: New methodology and findings. Economic and Political Weekly, 45(16), 65-71.

Dreze, J., \& Sen, A. (1989). Hunger and Public Action. Oxford University Press, New York.

Fiscella, K., \& Franks, P. (1997). Poverty or income inequality as predictor of mortality: Longitudinal cohort study. British Medical Journal, 314, 1724-1728.

GOI. (2019). National health accounts estimate for India 2016-17. Central Bureau of Health Intelligence, Directorate General of Health, Ministry of Health and Family Welfare, Government of India, New Delhi.

Hitiris, T., \& Posnelt, J. (1992). The determinants and effects of health expenditure in developed countries. Journal of Health Economics, 11, 173-181.

ILO. (2020). World employment and social outlook: Trends 2020. International Labour Organization, Geneva.

Kaplan, G. A., Pamuk, E. R., Lynch, J. W., Cohen, R. D., \& Balfour, J. L. (1996). Inequality in income and mortality in the United States: Analysis of mortality and potential pathways. British Medical Journal, 312, 999-1003.

Kleiman, E. (1974). The determinants of national outlay on health. In Perlman, M. (Ed.), The Economics of Health and Medical Care (pp. 66-81). Macmillan, London.

Kothari, V. N. (1996). Investment in human resources. The Indian Economic Association, Rapporteur Report, ix, Population Prakashan, Bombay.

Kumar, D. (2006). Trends and regional disparities in health sector. The Indian Economic Journal, 53(4), 43-71.

Kumar, D., \& Singh, B. (2015). Health sector in Bihar and Jharkhand: Status and challenges. Economic Journal of Bihar, 4(1), 329-350.

Lev, R. R. (1986). The public private mix and international health care cost. In A. J. Culyer, \& B. Jonsson (Eds.), Public and Private Health Services; Complementaries and Conflicts. Basil Blackwell, Oxford.

Link, B. G., \& Phelan, J. (1995). Social conditions as fundamental causes of disease. Journal of Health and Social Behavior, (Extra Issue), 80-94.

MOHFW. (2005). Financing and delivery of health care services in India. National Commission on Macroeconomics and Health, Ministry of Health and Family Welfare, Government of India, New Delhi.

MOHFW. (2012). RHS Bulletin. Ministry of Health and Family Welfare, Government of India, New Delhi.

MOHFW. (2018). National Health Profile, $14^{\text {th }}$ Issues. Central Bureau of Health Intelligence, Directorate General of Health, Ministry of Health \& Family Welfare, Government of India, New Delhi. 
MOHFW. (2019). National Health Profile, $14^{\text {th }}$ Issues. Central Bureau of Health Intelligence, Directorate General of Health, Ministry of Health \& Family Welfare, Government of India, New Delhi.

MOHFW. (2020). Demand for grants 2020-21 Analysis: Health and Family Welfare. Ministry of Health and Family Welfare, Government of India, New Delhi.

Nancy, E. A., \& Newman, K. (2002). Socio-economic disparities in health: Pathways and policies. Health Affairs, 21(2), 60-76.

NFHS. (2015). National Family Health Survey-4, 2015-2016. International Institute for Population Sciences, Mumbai.

Peters, D., Yezbeck, A., Sharma, R., Ramama, G., Pritchett, L., \& Wagstaff, A. (2002). Better health systems for India's poor: Finding, analysis and options. World Bank, Washington, D.C.

Pritchett, L., \& Summers, L. H. (1996). Wealthing is Healthier. Journal of Human Resources, 33, 841-868.

Rao, M. G., \& Choudhury, M. (2008). Inter-state equalization of health expenditure in Indian Union. National Institute of Public Finance and Policy, New Delhi.

Sen, A. (1998). Mortality as an indicator of economic success and failure. Economic Journal, 108(446), 1-25.

Sharma, S. S. P., \& Vijay Kumar, T. (2008), Growing rural-urban disparity in Bihar. National Institute of Rural Development, Hyderabad, and Serials Publication, New Delhi.

Registrar General of India. (2020). Special bulletin on Maternal Mortality in India 2016-18. Sample Registration System (SRS), Office of the Registrar General, Government of India, New Delhi.

UNDP. (2020). Human Development Report 2020. United Nations Development Programme, New York.

Wayne, J. R. (2012). Health disparities: Gaps in access, quality and affordability of medical care. Transactions of the American Clinical and Climatological Association, 123, 167-174.

WHO. (2001). World Health Report 2001. World Health Organization, Geneva.

WHO, World Bank, \& USAID. (2003). Guide to Producing National Health Accounts. World Health Organization, Geneva.

WHO. (2003). World Health Report: Shaping the Future. World Health Organization, Geneva.

WHO. (2020). World Health Statistics Reports, 2020. World Health Organisation, Geneva.

World Bank. (2015). World Development Indicators 2015. World Bank, Washington, D.C. 